\title{
ON SOME INEQUALITIES INVOLVING TRIGONOMETRIC AND HYPERBOLIC FUNCTIONS WITH EMPHASIS ON THE CUSA-HUYGENS, WILKER, AND HUYGENS INEQUALITIES
}

\author{
EDWARD NEUMAN AND JÓZSEF SÁNDOR
}

Abstract. Recently trigonometric inequalities of N. Cusa and C. Huygens (see, e.g., [9]), J. Wilker [11], and C. Huygens [4] have been discussed extensively in mathematical literature. We shall demonstrate that Wilker's inequality, Huygens' inequality, and some other related inequalities all follow from the Cusa-Huygens inequality. A generalization of the latter result is also obtained. The hyperbolic counterparts of those inequalities are also derived.

Mathematics subject classification (2010): Primary: 26D05, 26D07; secondary: 33B10.

Keywords and phrases: inequalities, trigonometric functions, hyperbolic functions, the Schwab-Borchardt mean.

\section{REFERENCES}

[1] A. BARICZ AND J. SÁNDOR, Extensions of generalized Wilker inequality to Bessel functions, J. Math. Inequal., 2, 3 (2008), 397-406.

[2] B.C. CaRlson, Algorithms involving arithmetic and geometric means, Amer. Math. Monthly, 78 (1971), 496-505.

[3] B.-N. Guo, B.-M. QIAO, F. QI, AND W. LI, On new proofs of Wilker inequalities involving trigonometric functions, Math. Inequal. Appl., 6, 1 (2003), 19-22.

[4] C. Huygens, Oeuvres Completes 1888-1940, Société Hollondaise des Science, Haga.

[5] D.S. Mitrinović, Analytic Inequalities, Springer-Verlag, Berlin, 1970.

[6] E. Neuman, One and two-sided inequalities for Jacobian elliptic functions and related results, Integral Transform. Spec. Funct. (2010), in press.

[7] E. Neuman, J. SÁndor, On the Schwab-Borchardt mean, Math. Pannon., 14, 2 (2003), 253-266.

[8] I. Pinelis, L'Hospital rules of monotonicity and Wilker-Anglesio inequality, Amer. Math. Monthly, 111 (2004), 905-909.

[9] J. SÁNDOR AND M. BENCZE, On Huygens' trigonometric inequality, RGMIA Res. Rep. Collection, 8, 3 (2005), Article 14.

[10] J.S. Sumner, A.A. Jagers, M. Vowe, And J. Anglesio, Inequalities involving trigonometric functions, Amer. Math. Monthly, 98 (1991), 264-267.

[11] J.B. Wilker, Problem E 3306, Amer. Math. Monthly, 96 (1989), 55.

[12] S. WU AND L. DEBNATH, A new generalized and sharp version of Jordan's inequality and its applications to the improvement of the Yang Le inequality, Appl. Math. Lett., 19, 12 (2006), 1378-1384.

[13] S. WU AND L. DEBNATH, A new generalized and sharp version of Jordan's inequality and its applications to the improvement of the Yang Le inequality, II, Appl. Math. Lett., 20,5 (2007), 532-538.

[14] S.-H. WU AND H.M. SRIVASTAVA, A weighted and exponential generalization of Wilker's inequality and its applications, Integral Transforms and Spec. Funct., 18, 8 (2007), 525-535.

[15] S.-H. WU AND H.M. SRIVASTAVA, A further refinement of Wilker's inequality, Integral Transforms and Spec. Funct., 19, 10 (2008), 757-765.

[16] S.-H. WU AND H.M. SRIVASTAVA, A further refinement of a Jordan type inequality and its applications, Appl. Math. Comput., 197 (2008), 914-923. 
[17] S.-H. Wu, H.M. SRivastava AND L. Debnath, Some refined families of Jordan type inequalities and their applications, Integral Transforms and Spec. Funct., 19, 3 (2008), 183-193.

[18] L. ZHU, A new simple proof of Wilker's inequality, Math. Inequal. Appl., 8, 4 (2005), 749-750.

[19] L. ZHU, On Wilker-type inequalities, Math. Inequal. Appl., 10, 4 (2007), 727-731. 